\title{
Serological and Epidemiological Studies of Helicobacter pylori Infection at District Mardan Based on Gender and Different Age Groups
}

\section{Ihteshamul Haq ${ }^{1}$, Shah Faisal ${ }^{2}$, Abdullah ${ }^{3,13^{*}}$, Muhammad Asgharr ${ }^{4}$, Ghazala Zarin Afridi ${ }^{5}$, Fazli Zahir $^{6}$, Sajid Iqbal ${ }^{3}$, Farkhanda7 , Abbas Khan ${ }^{8}$, Abid Ur Rehman ${ }^{9}$, Raza Ullah ${ }^{10}$, Fawad Ali ${ }^{11}$, Habib Ullah ${ }^{4}$, Muhammad Waqas ${ }^{12}$, and Adil Khan ${ }^{13}$}

${ }^{1}$ Graduate School of Biotechnology and Oriental medicine Kyunghee University Suwon, South Korea

${ }^{2}$ Department of Biotechnology, Bacha Khan University, KPK, Pakistan

${ }^{3}$ Department of Microbiology, Abdul Wali Khan University, Mardan, KPK, Pakistan

${ }^{4}$ Department of Pathology, Khyber Teaching Hospital Peshawar and Khyber Medical College Peshawar, KPK, Pakistan

${ }^{5}$ Department of Pathology, Khyber Girls Medical College, Hayatabad Peshawar, KPK, Pakistan

${ }^{6}$ Department of Allied Health Sciences, Iqra National University, Peshawar, KPK, Pakistan

${ }^{7}$ CAS Key Laboratory of Tropical Plant Resources and Sustainable Use Xishuangbanna Tropical Botanical Garden Chinese Academy of Sciences, Menglun, China

${ }^{8}$ Department of Biotechnology and Genetic Engineering, Kohat University of Science and Technology, Kohat, KPK, Pakistan

${ }^{9}$ Department of Genetics, Hazara University, Mansehra, KPK, Pakistan

${ }^{10}$ Department of Biotechnology, University of Malakand, Chakdara, KPK, Pakistan

${ }^{11}$ Department of Biological Sciences, International Islamic University, Islamabad, Pakistan

${ }^{12}$ Department of Biotechnology, Quaid-i-Azam University, Islamabad, Pakistan

${ }^{13}$ Department of Microbiology, Abasyn University, Peshawar, KPK, Pakistan

${ }^{*}$ Corresponding author: Abdullah, Department of Microbiology, Abdul Wali Khan University, Mardan, KPK, Pakistan, E-mail: abdul. 9353chd@gmail.com

Received date: June 15, 2020; Accepted date: June 18, 2020; Published date: June 29, 2020

Citation: Haq I, Faisal S, Abdullah, Asghar M, Afridi GZ, Zahir F, et al. (2020) Serological and Epidemiological studies of Helicobacter pylori infection at district Mardan based on gender and different age groups. J Biomed Sci Vol.9 No.3:8.

\section{Abstract}

The current study was aimed to observe the prevalence of Helicobacter pylori infection at District Mardan with respect to their gender and age groups. The blood samples were collected from all the subjects who attended the OPD at Mardan Medical Complex. All these samples were screened for the presence of antibodies against $H$. pylori through a rapid antibody assay. Positive and negative cases were recorded based on the test results and prevalence was measured keeping in mind the selected parameters in individuals of each group. A total of 4312 people was included in the study, out of which 2586 were males and 1726 were females. Majority of the patients were in the mature age group. Based on our results, there were 125 males demonstrating a prevalence of $4.83 \%$ which is slightly higher than $4.66 \%$ prevalence of 77 females infected. Comparisons were made based on gender and age groups and data presented in the form of figures and tables. Monthly wise prevalence has also been shown. Moreover, prevalence was higher in the people aged 19-44 and lowest in immature ones. However, the overall prevalence in the subjects was $4.68 \%$ for the span of 4 months.

Keywords: Helicobacter pylori; Seroepidemiology; Prevalence; Pakistan

\section{Introduction}

Helicobacter pylori are spiral shaped gram-negative bacteria which infects more than $30 \%$ population worldwide and, in few countries, this infects more than $50 \%$ people of the total population. Marshall and Warren were awarded Nobel Prize in 1982 for the discovery of this bacterium. It is one of the most studied bacteria and over 29000 articles established its importance in human disease. This bacterium is responsible for gastritis, gastric and duodenal ulcer and gastric cancer [1]. Globally different strains of $H$. pylori seem to be associated with differences in virulence, and the resulting interplay with host and environmental factors leads to subsequent differences in the expression of disease. Age, ethnicity, sex, geography and socioeconomic status are all factors that influence the incidence and prevalence of $H$. pylori infection. In developing countries, $H$. pylori infection is a public health 
issue. The high prevalence of the infection means that public health interventions may be required. Therapeutic vaccination is probably the only strategy that would make a decisive difference in the prevalence and incidence of $H$. pylori throughout the world. The overall prevalence is higher in developing countries and lower in developed countries and within areas of different countries. There may be similarly wide variations in the prevalence between more affluent urban and rural populations. The principal reasons for these variations involve socioeconomic differences between populations. Transmission of $H$. pylori is largely by the oral-oral or faecal-oral routes. Lack of proper sanitation, safe drinking water, basic hygiene, poor diets and overcrowding all play a role in determining the overall prevalence of Helicobacter pylori infection [2]. In 1994, Helicobacter pylori was categorized as a class I human carcinogen by the WHO International Agency for Research on Cancer (IARC) due to its epidemiological connection to gastric cancer [3].

In Pakistan, acid peptic disease due to the prevalence of Helicobacter pylori infection is very high among population and the number of patients is continuously increasing mainly due to non-availability of ideal diagnostic and treatment facilities in public healthcare sector. As $H$. pylori is a rising issue in Pakistan, so according to experts of health $H$. pylori infection may become chronic with the chances of gastric carcinoma and stomach cancer, if it is not treated fully and properly [4].

The existence of spiral shaped micro-organisms like $H$. pylori in the stomach of human was observed at least 100 years before by Prof W. Jaworski who was a Polish Clinical Researcher at the Krakow Jagiellonian University. Health experts believe that in order to decrease the chances of stomach cancer, Helicobacter pylori infection should be treated properly and the bacterium should be eliminated completely from the body. Half population of the world is affected with Helicobacter pylori infection but still the way of transmission has not been completely clarified. There are some indications in order to propose that it is transmitted from individual to individual through the fecal oral way but still the way of transmission is undecided and faecal to oral or oral to oral are the most commonly routes of transmission at this phase. Although most infections happen in childhood, Helicobacter pylori infect both male and female equally. The presence of Helicobacter pylori in stomach persuades a chronic, active, inflammation in approximately every individual who is infected. Majority of the individuals with Helicobacter pylori are, however, asymptomatic and there are less than $10 \%$ of persons with Helicobacter pylori in which appear peptic ulcer disease, Mucosa Associated-Lymph-Tissue (MALT) lymphoma or gastric cancer. Symptoms of $\mathrm{H}$. pylori in anybody appear when it damages his stomach's lining or top part of his duodenum [5].

\section{Materials and Methods}

\section{Study site}

This present study was conducted from $1^{\text {st }}$ of September 2017 to $30^{\text {th }}$ December 2017 at Mardan Medical Complex and Teaching Hospital, KP with an aim to assess the prevalence of Helicobacter pylori infection across population in district Mardan.

\section{Data and samples collection}

A total of 4312 patients which included referrals from both outpatient and hospital inpatient services were taken onto consideration. Among them, 2586 were males and 1726 were females. All the patients were further sub-divided into three groups based on their age, i.e. immature, mature and adults. Blood samples were taken and sent to pathology laboratory for further analysis. These patients were included only once in the process.

\section{H. pyloritest}

Blood antibody test named as $H$. pylori Ab rapid assay was carried out to assess antibodies formed against $H$. pylori bacteria in the serum. Approximately $30 \mu \mathrm{l}$ drop of serum was transferred into the test strips and one drop of $40 \mu \mathrm{l}$ buffer was added. After few minutes, a coloured line appeared and results were recorded. Two distinct red lines appear, one line in the control region (C) and second in test region $(T)$, showed positive results. Appearance of red line only in the control region (C) and not in the test region demonstrated negative results. The concentration of red colour in the test line region $(\mathrm{T})$ varies depending on the conception of $H$. pylori antibodies in the sample. Hence, any shade of red colour in the test region $(T)$ was reflected as positive.

\section{Data analysis}

Statistical analysis of the data was performed using MS Excel. Percentages and values were presented in the form of figures and tables and comparisons were made among them.

\section{Results}

All the data has been presented in the form of figures and tables to illustrate the number of normal and infected individuals, prevalence on monthly and gender basis and also comparison in different age groups. In this study, a total of 4312 patients were screened for anti $H$. pylori (Helicobacter pylori) antibody by rapid assay (serum method). It was found that 202 patients were positive for Helicobacter pylori infection as depicted in Figure 1 and Table 1, with an overall prevalence of $4.68 \%$. Table 1 illustrates that there are 125 male patients positive for anti $H$. pylori antibody with the prevalence value of $4.83 \%$ and among them, 11 are immature patients having age of 3-18 year are Helicobacter pylori positive which show $4.18 \%$ prevalence in immature male 
patient, while 78 mature male patients of the age 19-44 years are positive for Helicobacter pylori infection which show $5.49 \%$ and 36 male adults having the age of 45-65 are positive for Helicobacter pylori infection which show $3.98 \%$ prevalence.

Table 1: Number and Helicobacter pylori prevalence of normal and infected people of different genders and varied ages.

\begin{tabular}{|c|c|c|c|c|c|c|}
\hline & Type & $\begin{array}{l}\text { Age } \\
\text { (in } \\
\text { year } \\
\text { s) }\end{array}$ & $\begin{array}{l}\text { Subje } \\
\text { cts }\end{array}$ & $\begin{array}{l}\text { Norm } \\
\text { al }\end{array}$ & $\begin{array}{l}\text { Helicobac } \\
\text { ter pylori } \\
+\end{array}$ & $\begin{array}{l}\text { Prevale } \\
\text { nce (\%) }\end{array}$ \\
\hline \multirow[b]{3}{*}{$\begin{array}{l}\text { Overa } \\
\text { II }\end{array}$} & $\begin{array}{l}\text { Immat } \\
\text { ure }\end{array}$ & $\begin{array}{l}03-1 \\
8\end{array}$ & 487 & 470 & 17 & 3.5 \\
\hline & Mature & $\begin{array}{l}19-4 \\
4\end{array}$ & 2402 & 2274 & 128 & 5.32 \\
\hline & Adult & $\begin{array}{l}45-6 \\
5\end{array}$ & 1423 & 1366 & 57 & 4.05 \\
\hline Total & & & 4312 & 4110 & 202 & 4.68 \\
\hline \multirow[b]{3}{*}{ Males } & $\begin{array}{l}\text { Immat } \\
\text { ure }\end{array}$ & $\begin{array}{l}03-1 \\
8\end{array}$ & 263 & 252 & 11 & 4.18 \\
\hline & Mature & $\begin{array}{l}19-4 \\
4\end{array}$ & 1420 & 1342 & 78 & 5.49 \\
\hline & Adult & $\begin{array}{l}45-6 \\
5\end{array}$ & 903 & 867 & 36 & 3.98 \\
\hline Total & & & 2586 & 2461 & 125 & 4.83 \\
\hline \multirow[b]{3}{*}{$\begin{array}{l}\text { Fema } \\
\text { les }\end{array}$} & $\begin{array}{l}\text { Immat } \\
\text { ure }\end{array}$ & $\begin{array}{l}03-1 \\
8\end{array}$ & 224 & 218 & 6 & 2.67 \\
\hline & Mature & $\begin{array}{l}19- \\
44\end{array}$ & 982 & 932 & 50 & 5.09 \\
\hline & Adult & $\begin{array}{l}45-6 \\
5\end{array}$ & 520 & 499 & 21 & 4.03 \\
\hline Total & & & 1726 & 1649 & 77 & 4.66 \\
\hline
\end{tabular}

Out of 202 positive cases, 77 are female positive patients in a total of 1726 females as obvious from Table 1, which show $4.66 \%$ prevalence. Among them, there are 6 immature female patients in the age of 3-18 which is $2.67 \%$, while out of 77 female patient just 50 number of patient are positive in the mature female in the age of $19-44$ which show $5.09 \%$ prevalence, and just 21 are positive in the adult female their age is $45-65$ which show $4.03 \%$ prevalence.

From Figure 1, it is clear that in the month of January, total patients were 1208 and out of them 59 were infected with Helicobacter pylori showing the prevalence of $4.88 \%$, while in February, 812 patients are registered and out of them, 21 were positive having prevalence are $2.58 \%$.

\section{H. Pylori prevalence in District Mardan}

$$
\text { 口Total } \mathbf{\square} \text { H.P Positive } \quad \text { H.P Negative }
$$
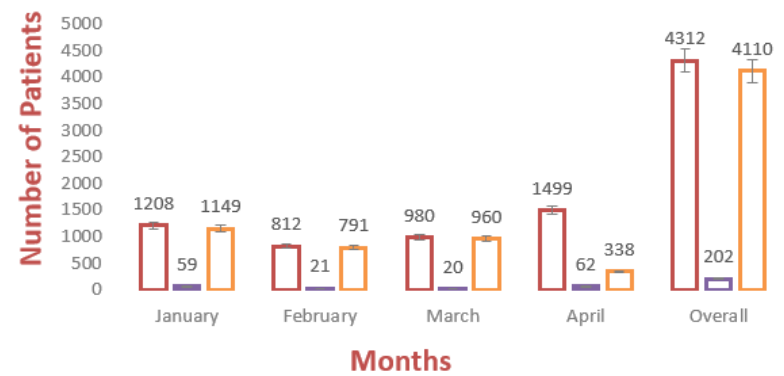

Figure 1: Number of Helicobacter pylori infected individuals among patients in Mardan during the span of 4 months.

In the following month of March, total number of patients are 980 and number of cases confirmed for Helicobacter pylori were 20 and the prevalence ratio are $2.04 \%$. In April, total positive patients were 62 out of 1499, which shows $4.14 \%$ prevalence. All this information is available both from Figures 1 and 2.

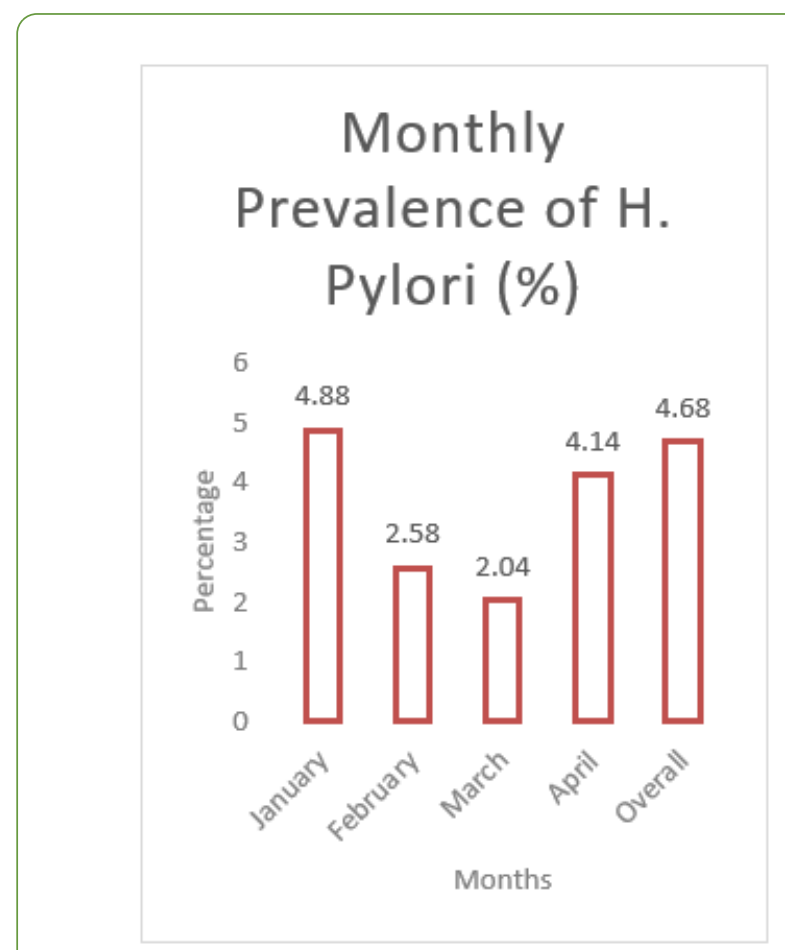

Figure 2: Percent prevalence on monthly basis.

Moreover, Figure 3 depicts the prevalence and percentage of infected and normal individuals in percent based on different age groups regardless of the gender. Helicobacter pylori prevalence is higher i.e. 5.32 in mature individuals followed by adults and then immature individuals. 


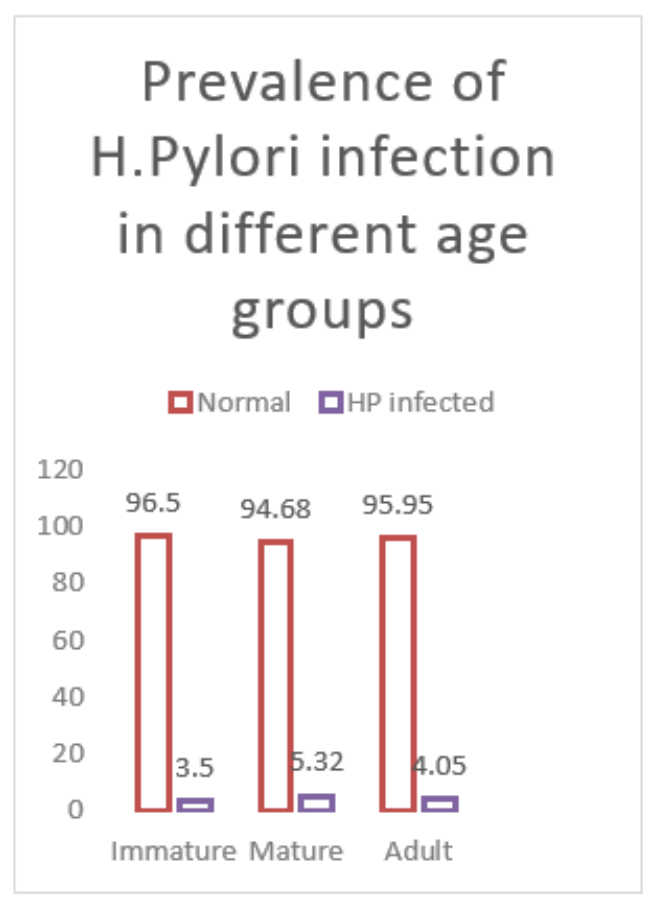

Figure 3: Percent of normal and infected individuals in different age groups.

\section{Discussion}

Helicobacter pylori is a harmful gram-negative bacterium infecting more than $30 \%$ population of the world and in few countries, above $50 \%$ of people are victims of the disease due to $H$. pylori infection [6]. H. pylori is considered to be the leading cause of human gastritis, duodenal and gastric ulcers and has been categorized as class-1 human carcinogen [7]. Usually the disease progress through gastritis as a result of $H$. pylori infections followed by atrophy, intestinal metaplasia and dysplasia that can cause gastric mucosal carcinoma. Gastritis is developed in almost $90 \%$ individuals infected with $\mathrm{H}$. pylori whereas gastric atrophy and intestinal metaplasia appear more often in $H$. pylori positive than in negative patients [8]. Genetic diversity and origin of the infecting $H$. pylori strain are the major factors that determine the outcome of $H$. pylori disease in most cases [9]. Virulent $H$. pylori cytotoxic-associated gene A (cag A) positive strains are associated with more severe state as patients infected with cag $A$ positive strains had higher risk of gastric cancer development than those of cag $A$ negative strains. Various studies reported that $60 \%-70 \%$ of $H$. pylori strains isolated from North American and European populations had cag A gene [10]. A study conducted at Abakaliki by Ugwu had shown that majority of Helicobacter pylori infected patients were more than 60 years of age [11]. The percentage of active $H$. pylori infection in the Northern region of Pakistan showed 53\% of prevalence [12]. A high rate of active $H$. pylori infection (74.4\%) in asymptomatic subjects in a rural area of Islamabad Pakistan has been reported [9]. Several epidemiological reports have shown that the rate of $H$. pylori infection increases significantly with age, with more than $80 \%$ of children being infected by the age of 10 years [13]. The variation in the prevalence of $H$. pylori infection between different populations suggests that different parameters such as socioeconomic status and environmental factors play a key role in the positivity of $H$. pylori infection [14].

In the current study we have examined 4312 hospital patient and general OPD patient from January 2017 to April 2017 for Anti H. pylori antibodies patients who were coming from different regions of Mardan KP, Pakistan to Mardan Medical Complex. The patients were screened for Anti $H$. pylori infection by $A b$ rapid assay (serum method) which showed an overall prevalence rate of $4.68 \%$. Out of total patients screened, 125 were positive in males and 77 in females for anti $H$. pylori antibody with the prevalence of 4 . $83 \%$ and $4.465 \%$ respectively. In Mardan, most of the patient screening for detecting $H$. pylori is done by local laboratory which show inaccurate results. This large variation in percent prevalence of the present study compared to other studies at different regions of Pakistan could be due to the type of test type used to diagnose the disease, false negative cases and low standards of the pathology centre. Moreover, it is also likely that most of the patients go for check-up, diagnosis and treatment to private medical centres and labs and therefore are not registered in the hospital where we performed our study. So, we recommended that people must be use standard laboratory for the diagnosis of $H$. pylori infection and demand from government that health facility must be provided. Improvement in the treatment and diagnosis of $H$. pylori infection should be made. Also, aware the people of Mardan KP and all Pakistan about $H$. pylori infection and their precautionary measures. Patients of $H$. pylori infection records and serum of all patients were reported to and analyzed at the Mardan Medical Complex, Pakistan from September 2019 to December 2019.

\section{Conclusion}

The current study highlights the total number of patients screened in the given span of time to assess the prevalence of Helicobacter pylori infected individuals across Mardan region. No significant difference has been noticed based on gender in prevalence of Helicobacter pylori, although it varies to some extent in different aged individuals. There is need to further explore the transmission routes and risk factors of the disease in the area under consideration. Standard diagnostic and quality treatment in addition to prophylactic and preventive measures can prove as quality tools to eradicate this infection completely from the population.

\section{Acknowledgment}

We are grateful to Mardan Medical Complex and Teaching Hospital, KPK, Pakistan for providing research facilities. 


\section{Authors Contributions and Consent}

Haq I contributed to the main idea, conceptualization and performing the research work. Faisal $S$ contributed in the data collection. Abdullah have contribution in formatting the manuscript draft and creating figures and tables. Asghar $M$, Afridi GZ, Zahir F, Iqbal S, Farkhanda, Khan A, Rehman AU, Ullah $\mathrm{R}$, Ali $\mathrm{F}$, Ullah $\mathrm{H}$, Waqas $\mathrm{M}$ and Khan $\mathrm{A}$ have contribution in the statistical and critical analysis of the manuscript and also help in proofreading. All authors are agreeing to the publication of this article in Journal of Biomedical Sciences.

\section{Funding Source}

Not applicable.

\section{Conflict of Interest}

The authors declare no conflict of interest.

\section{Reference}

1. Kazuhiko TF, Ichizen T, Ohkusa T, Kumagai J, Tanizawa T, et al. (2000) Endoscopic and histological comparison of nodular Dyspepsia with and without Helicobacter pylori infection evaluated by modified Sydney system. Am J Gastroenterol 95: 2195-2199.

2. IARC (1994) Infection with Helicobacter pylori. IARC Monogr Eval Carcinog Risks Hum 61: 177-240.

3. Uemura $\mathrm{N}$, Okamoto $\mathrm{S}$, Yamamoto $\mathrm{S}$, Matsumura $\mathrm{N}$, Yamaguchi S, et al. (2001) Helicobacter pylori infection and the development of gastric cancer. N Engl J Med 345: 784-789.

4. Mehmood K, Awan AA, Muhammad N, Hasan F, Nadir A (2014) Helicobacter Pylori prevalence and histopathological findings in dyspeptic patients. J Ayub Med Coll Abbottabad 26: 182-185.

5. Tummuru MK, Cover TL, Blaser MJ (1993) Cloning and expression of a high-molecular-mass major antigen of Helicobacter pylori: evidence of linkage to cytotoxin production. Infect Immun 61: 1799-1809.
6. Butt AK, Khan AA, Izhar $M$, Alam A, Shah SWH, et al. (2002) Correlation of Helicobacter pylori in dental plaque and gastric mucosa of dyspeptic patients. J Pak Med Associat 52: 196.

7. Hunt RH, Xiao SD, Megraud F, LeonBarua R, Bazzoli F, et al. (2011) World gastroenterology organization global guideline: Helicobacter pylori in developing countries. J Clin Gastroenterol 45: 383-388.

8. Craanen ME, Dekker W, Blok P, Ferwerda J, Tytgat GN (1992) Intestinal metaplasia and Helicobacter pylori: an endoscopic bioptic study of the gastric antrum. Gut 33: 16-20.

9. Rasheed F, Ahmad T, Bilal R (2011) Frequency of Helicobacter pylori infection using 13C-UBT in asymptomatic individual of Barakaho, Islamabad Pakistan. J Coll Physician Surg Pak 21: 379-381.

10. Kuipers EJ, Peña AS, Festen HP, Meuwissen SG, Uyterlinde $A M$, et al. (1995) Long-term sequelae of Helicobacter pylori gastritis. Lancet 345: 1525-1528.

11. Ugwu N, Ugwuja E, Ejikeme B, Obeka N (2008) Helicobacter pylori seropostivity in Nigerians with Type 2 Diabetes mellitus. Int J Trop Med 4: 32-36.

12. Khan A, Farooqui A, Raza Y, Faisal R, Hamid M, et al. (2012) Prevalence, diversity and disease association of Helicobacter pylori in dyspeptic patients from Pakistan. J Infect Dev Ctries 7: 220-228.

13. Ertem D, Harmanci H, Pehlivanoglu E (2003) Helicobacter pylori infection in Turkish preschool and school children: Role of socioeconomic factors and breast feeding. Turk J Pediatr 45: 114-122.

14. Klein PD, Opekun AR, Smith EO, Graham DY, Gaillour A (1991) Water source as risk factor for Helicobacter pylori infection in Peruvian children: Gastrointestinal physiology working group. Lancet 337: 1503-1506. 